\title{
Linguagem visual e princípios de design em ebook interativo infantil
}

\section{Visual grammar and the principles of design on children's interactive ebook}

Deglaucy Jorge Teixeira Juliane Vargas Nunes Berenice S. Gonçalves

Richard Perassi Luiz de Sousa 


\section{Resumo}

O livro infantil ilustrado apresentado em suportes digitais permite o incremento de recursos visuais interativos, elementos dinâmicos e estímulos sonoros. Este artigo, entretanto, apresenta um estudo descritivo-analítico que, especificamente, trata da estrutura visual do ebook infantil Treasure Kai and the Lost Gold Shark Island. Considera-se a linguagem visual do produto, descrevendo o arranjo dos elementos visuais básicos junto aos princípios de design como estratégia de comunicação na interface multimídia. Tais questões definem a organização visual da publicação, que deve ser legível e coerente com o sentido geral da mensagem. Com base neste estudo, identificaram-se estratégias utilizadas para definir a linguagem visual do ebook infantil. Dentre elas, destacam-se os códigos formais e cromáticos utilizados para diferenciar os objetos interativos, tratamentos específicos em planos de fundo para indicar as mudanças ocorridas na narrativa e contrastes que contribuem para hierarquizar os elementos no processo de leitura em ambiente digital.

Palavras-chave: Livro Infantil ilustrado; Book app infantil; Linguagem Visual.

\section{Abstract}

The picturebook, also presented in digital media allows growth of interactive features, dynamic elements and sound stimuli. This article, however, presents a descriptive-analytical study that specifically addresses the visual structure of child ebook Treasure Kai and the Lost Gold Shark Island. The visual syntax of the product is considered, describing the basic arrangement of visual elements in the principles of design as a communication strategy in multimedia interface. Such questions define the visual organization of the publication, which must be legible and consistent with the general meaning of the message. Based on this study, we identified strategies used to define the visual graph structure of child ebook. Among them, there is the formal, color and textures used to differentiate interactive objects, specific treatments backgrounds characteristics to indicate the changes in history and contrasts that contribute to rank the elements in the process of reading in the digital environment.

Keywords: Picturebook; Children's book app; Visual grammar.

ISSN: $2175-2346$ 


\section{INTRODUÇÃO}

O ebook Treasure Kai and the Lost Gold Shark Island é um exemplo de última geração dos produtos editoriais decorrentes da evolução tecnológica que tem permitido o surgimento e a difusão dos livros digitais. Atualmente, a partir da popularização dos dispositivos digitais, os livros eletrônicos (ebooks) têm sido projetados para serem lidos em smartphones, e-readers e tablets. Além das ferramentas hipermidiáticas já utilizadas em ambientes acessados a partir de computadores pessoais, os ebooks para dispositivos móveis podem lançar mão da manipulação por toque e gestos no processo de interação do leitor a partir de uma tela touch screen.

Um projeto, porém, voltado para dispositivos móveis requer a adequação do formato gráfico para um layout em mídia digital, envolvendo o planejamento da linguagem visual em termos de dimensão, orientação, resolução, dentre outras questões para efetivar a mensagem. Essa linguagem designa os fenômenos de significação visual por ela gerados. Dessa forma, hoje a linguagem visual se reconstrói como um importante objeto contemporâneo de investigação para o Design (LESSA, 2006).

Assim, este artigo apresenta um estudo descritivo-analítico sobre a linguagem visual do ebook infantil Treasure Kai and the Lost Gold Shark Island, que tem como suporte o iPad (tablet da Apple), buscando compreender a relevância da escolha, tratamento e organização dos elementos visuais em sua interface. Por meio deste estudo pretende-se identificar estratégias na definição da linguagem visual de um ebook infantil, as quais possam promover a compreensão do texto e a leitura interativa no ambiente digital.

\section{Livro infantil ilustrado}

Os livros infantis são classificados, segundo Linden (2011), de acordo com a disposição interna do conteúdo: livros com ilustração, primeiras leituras, livros ilustrados, histórias em quadrinhos (HQ), livros pop-up, livros-brinquedo, livros interativos e livros imaginativos.

O livro infantil ilustrado é a obra literária direcionada a crianças, para as quais a imagem predomina, sendo a narrativa articulada entre texto e imagem, com a possibilidade de apresentar-se em vários gêneros e suportes. Os tipos de livros infantis podem assumir diferentes materialidades, que interferem na sua compreensão, como livro cartonado, de plástico, livro-CD e atualmente o ebook. A obra pode ainda diferenciar-se em gêneros como contos, poesia, histórias policiais, documentários, etc (LINDEN, 2011).

As inovações relacionadas à sua materialidade ampliam a concepção tradicional do livro como objeto. Para Linden (2011), a materialidade do livro infantil ilustrado não desvia seus princípios de funcionamento, desde que tenha sido bem planejado na fase de concepção, embora possa enriquecer ou limitar suas possibilidades expressivas. 


\section{Book app infantil}

Diferente do livro impresso, que é ao mesmo tempo o suporte e o conteúdo do livro, o formato digital necessita de um mecanismo físico - o hardware, que pode ser um computador pessoal, um smartphone, um tablet ou um e-reader; de um leitor de arquivo -, um software de leitura, para abrir o arquivo; e o livro propriamente dito - o arquivo ebook (SPALDING, 2012).

Assim como um arquivo de texto (doc ou txt) precisa do software específico para acessá-lo, os ebooks necessitam de dispositivos específicos e software compatível para cada formato de arquivo.

De acordo com Duarte (2010), ebook é um termo genérico, podendo existir vários formatos de arquivo nesta categoria como PDF, ePub, AZM e APP. O formato aplicativo (book app), um software executável, destaca-se dos demais por apresentar maior possibilidade interativa e não necessitar de outro software para acessá-lo.

Neste contexto, o book app infantil consiste em um livro infantil ilustrado no formato de aplicativo. Segundo Teixeira et al. (2013), no book app infantil a ilustração é mais um recurso do texto não verbal dentro do ambiente digital que assume sua importância como integrante do texto verbal. Assim, um book app infantil bem-sucedido deve preencher os requisitos de um livro infantil ilustrado tradicional, mas com o potencial extra permitido pelo ambiente digital (BIRCHER, 2012).

\section{Design do livro infantil ilustrado}

Quando texto e imagem estão devidamente combinados, o livro ilustrado funciona como uma unidade, e desta forma sua concepção é feita em um único design (CULLINAN et al., 2014). A combinação da arte verbal e visual é mais complexa do que um trabalho artístico, pois funciona como uma parte vital de um trabalho literário, no qual frequentemente informações e significados não presentes no texto são adicionados por meio da linguagem visual para criar história dentro da história.

O design do livro ilustrado envolve mídias, técnicas e estilos. Seu meio de produção está relacionado ao material utilizado como lápis, tinta, papel, computador, dentre outros. A técnica pode envolver pintura, colagem, fotografia, etc. Ao combinar o meio com a técnica, o designer estabelece um estilo próprio que expressa o tema, transmite informações, explica o conceito e ambienta a história.

Esta composição visual deve ser organizada na página, a fim de compor o projeto do livro. Esta estruturação é feita com os elementos básicos da linguagem visual: ponto, linha, plano, mancha, formas e texturas. E com os princípios de design: ritmo, equilíbrio, variedade, ênfase, ordem espacial e unidade, unificando o conteúdo para transmitir significado (CULLINAN et al., 2014).

Estes elementos visuais são compartilhados pelos diferentes campos que lidam com a visualidade. Portanto, sendo utilizados também para a configuração dos livros ilustrados infantis em outras tecnologias, como os book apps, em formato digital. Desta forma, a linguagem visual também estuda as artes visuais, fundamental para composição do espaço na interface ${ }^{1}$ digital.

1 De acordo com Bevilacqua (2007), a interface é o espaço (imaterial) que surge da interação entre usuário e não deve ser confundida com objeto, e não o objeto em si. Contudo, existem situações em que é difícil dissociá-los, como é o caso da interface digital em que a tela representa ao mesmo tempo o espaço e 0 objeto de interação. 


\section{LINGUAGEM VISUAL}

De acordo com Lessa (2006) a categoria de linguagem visual pode ser compreendida "como conjunto aberto cuja identidade continuamente se transforma a partir de uma dinâmica de reconhecimento a posteriori". E, juntamente com ela, deve ser privilegiada a categoria de enunciação visual, a qual implica esquemas práticos e/ou simbólicos de articulações significantes que podem limitá-la, sugeri-la ou colocar-se como ponto de superação, considerando não apenas um sistema único, mas suas unidades sistêmicas de construção significante, com uma visão analítica mais concreta.

Apesar das diferenças culturais, há um sistema visual perceptível a todos os seres humanos, capaz de organizar os elementos visuais para facilitar a compreensão da mensagem por meio da linguagem visual. São eles: ponto, linha, forma, plano, tom, cor, textura, escala ou proporção, dimensão e movimento.

\section{Elementos básicos da linguagem visual}

Para este estudo selecionaram-se nove elementos básicos da linguagem visual, cuja reunião e ordenação pode compor a representação das coisas visualmente percebidas, sendo elas: ponto, linha, plano, mancha, forma, cor, textura, espaço e volume.

De acordo com sua dimensão, posição e relação com os elementos que o circundam, o ponto pode destacar-se ou misturar-se à massa. Assim, uma série de pontos pode formar uma linha, uma massa de pontos pode tornar-se uma textura, forma ou plano. A linha exerce funções de demarcação espacial e configuração, expressando formas e figuras e delimitando a união entre dois planos. Quando atinge certa espessura, a linha torna-se um plano; e quando multiplicada, pode gerar também volumes e texturas.

$\mathrm{Na}$ representação bidimensional, o plano é considerado e representado como uma mancha uniforme, na qual não se percebe variações cromáticas ou tonais. Um plano com limites definidos consiste em uma forma. Já a mancha é o elemento determinante da linguagem pictórica ou fotográfica, porque apresenta variações cromáticas e tonais. Sobre esses elementos gráfico-expressivos atuam aspectos que os qualificam, como cor, textura, espaço e volume.

A cor é a qualidade mais rapidamente assimilada pelo observador, apreendida antes mesmo da forma. As cores possuem significados, que são transferidos para a forma à qual é aplicada. Atuando de forma associada à cor, a textura é a qualidade tátil da superfície dos objetos, percebida a partir do contato das mãos, mas também da visão. As texturas exploram qualidades como áspero ou liso, firme ou esponjoso, irregular ou liso. Também simulam materiais e técnicas, como nas texturas com pinceladas aparentes, traços a lápis ou carvão.

O espaço atrai a atenção do espectador para os objetos na página e pode criar a ilusão de distância. A falta de espaço pode gerar desconforto, confusão e caos. O uso generoso de espaço sugere serenidade, mas também pode significar vazio, solidão e isolamento. A representação de volume no plano bidimensional se utiliza de convenções gráficas, dentre elas, a perspectiva (LUPTON, 2008).

A partir desses elementos, no contexto do design são criadas imagens, ícones, padrões e tipografias, com os quais se compõem as mensagens visuais (LUPTON, 2008). 
Para isso, tais elementos são organizados e qualificados a partir da aplicação de princípios de design.

\section{Princípios de design}

Os princípios de design são regras e conceitos para organizar e otimizar os elementos visuais em um plano bidimensional, assim como uma receita combina seus ingredientes. Os princípios de design, segundo Costelo et al. (2012), podem ser divididos em três categorias: Unificação, Ênfase e Força de percepção.

\section{Unificação}

Quando as informações estão organizadas sem critério ou simplesmente desorganizadas, o cérebro trabalha mais para encontrar um significado. Mas quando o conteúdo é organizado conforme os princípios de design, o cérebro pode trabalhar mais rápido e a comunicação será mais efetiva. O princípio de Unificação inclui Proximidade, Alinhamento, Similaridade e Repetição.

Proximidade: É mais provável que se entenda a relação entre os objetos quando estão juntos, como usar título próximo da imagem a que se refere. Geralmente a proximidade é usada com espaço brando para manter o grupo de objetos mais perceptível.

Alinhamento: $O$ princípio do alinhamento posiciona os objetos juntos a uma aresta ou linha. Em uma página ou múltiplas páginas, o alinhamento deve ter consistência e facilitar a leitura. Não é recomendado variar os tipos de alinhamento.

Similaridade: $O$ cérebro percebe o relacionamento em um grupo de objetos visuais a partir da semelhança ou uniformidade do estilo de seus atributos.

Repetição: Está diretamente ligada à similaridade, pois sugere repetições de elementos gráfico-visuais como linha, cor, forma e textura em diferentes objetos para fortalecer a unidade visual.

\section{Ênfase}

O princípio da Ênfase deve destacar o centro ou ponto de interesse principal. Em um jornal, por exemplo, a frase escrita em caracteres de maior tamanho é projetada para chamar a atenção do leitor para o que se acredita ser a notícia mais importante do dia.

A Ênfase pode ser usada como um guia rápido de navegação em uma mídia digital. A variação de tamanho dos elementos no espaço visual é uma das formas mais comuns de enfatizar uma informação, entretanto existem outras formas que podem ser exploradas como Contraste, Cor, Profundidade e Proporção (COSTELO et al., 2012).

Contraste: O contraste, de acordo com Gomes Filho (2000), é uma contraforça à tendência do equilíbrio absoluto e tem a função de estimular e atrair a atenção. $O$ contraste pode estar relacionado à diferença cromática, como o texto preto em um fundo branco que se mostra como o melhor contraste para leitura.

Cor: Atua também como princípio de design. Segundo Costelo et al. (2012), a cor é a mais poderosa ferramenta para gerar contraste e enfatizar objetos no espaço visual. Um ponto de cor, por exemplo, pode rapidamente direcionar o foco da visão, principalmente se forem cores quentes, mais atrativas ao olho humano. Mas deve-se evitar o 
uso exagerado deste recurso para não causar opressão ao leitor.

Profundidade: Relaciona-se com o princípio de percepção figura-fundo. É largamente utilizada nos objetos visuais por meio de sombras, luzes, perspectivas e outros efeitos para simular uma aparência de profundidade.

Proporção: É a escala relativa de um objeto visual comparado a outro em uma composição.

\section{Força de percepção}

Quando o leitor olha para uma representação gráfica em uma tela, seu cérebro recebe constantes impulsos de atração dentro do espaço visual. Independentemente de ver uma fotografia em cima de uma mesa ou em um quadro na parede, tende-se a perceber um direcionamento da parte de cima para baixo. Mas esta percepção não está ligada ao campo gravitacional e sim à força do campo visual que pode direcionar a leitura. Espaços brancos podem funcionar como espaços de respiro em volta dos objetos visuais e até neutralizar a força visual da tela. Os princípios ligados à experiência de força de percepção são Equilíbrio, Continuidade, Figura-fundo e Fechamento psicológico (COSTELO et al., 2012).

Equilíbrio: Acontece quando o peso visual dos objetos está bem distribuído na composição. O senso de equilíbrio pode ser alcançado por meio da escala, cor ou posição dos objetos no espaço visual de forma simétrica, quando ambos os lados do espaço estão opostos e equivalentes, ou assimétrica, quando a equivalência é estabelecida por objetos de diferentes tamanhos, cor e tom.

Continuidade: Neste princípio o cérebro tende a processar o que se vê em uma linha contínua e previsível livre de obstáculos e de mudança de direção.

Figura-fundo: Na psicologia da Gestalt, um elemento que é percebido em primeiro plano é denominado figura e o que fica por trás, fundo.

Fechamento psicológico: Acontece quando as informações parciais são completadas mentalmente.

\section{PROCEDIMENTOS METODOLÓGICOS}

Como objeto da análise, foi definido o book app infantil Treasure Kai and the Lost Gold Shark Island, que se destaca por sua lista de premiações, além de ser aprovado com o selo QED (Quality, Excellence, Design) e ser um dos 20 book apps ganhadores de cinco estrelas pelo prêmio da Digital Storytime 2012.

Buscando viabilizar a análise, foram selecionadas e capturadas, na forma de imagens estáticas, algumas de suas telas. Posteriormente, essas telas foram descritas e analisadas a partir de sete elementos básicos da linguagem visual pré-definidos a partir da literatura: linha, forma, plano, cor, textura, espaço e volume, no atendimento de três princípios de design: Unificação, Ênfase e Força perceptual. Os elementos visuais ponto e mancha não foram analisados individualmente por estarem associados aos demais, nas telas selecionadas.

Por fim, os dados da análise foram discutidos, dando origem a considerações sobre a linguagem visual no design de um ebook infantil no formato book app. 


\section{RESULTADOS}

Para esta análise foram selecionadas quatro telas do book app Treasure Kai and the Lost Gold Shark Island, de acordo com os diferentes contextos e ambientações da história.

Treasure Kai and the Lost Gold Shark Island é um book app da empresa Treasure Bound Books Pty Ltd produzido para iPad, indicado para crianças de quatro a nove anos, texto autoria de Karen Guinn Robertson e ilustração de Victor Guisa.

Este book app narra uma história de aventura sobre um menino chamado Kai, que sonha em encontrar um tesouro perdido. Seu conteúdo é composto por ilustrações, animações, trilha sonora, caixas de texto, sons interativos e narração. Sua navegação é linear e oferece, a partir de um determinado ponto da narrativa, oito trajetórias possíveis por meio de links representados por imagens de baús. Em todas as telas a narrativa é apresentada na forma de texto e áudio. Os comandos de controle do áudio são oferecidos junto ao texto dentro de uma caixa de diálogo, que pode ser deslocada pelo usuário para qualquer lugar da tela com um gesto de arrastar.

Também são disponibilizados outros recursos de interação como o ícone para retorno a tela inicial, presente em todas as telas, e textos e objetos nos quais o usuário precisa clicar para avançar a narrativa. A primeira tela (Fig. 1) corresponde ao início da narrativa - na qual o protagonista, Kai, apresenta sua história ao leitor por meio da narração - e uma caixa de diálogo que o texto vai destacando à medida que as palavras estão sendo faladas.

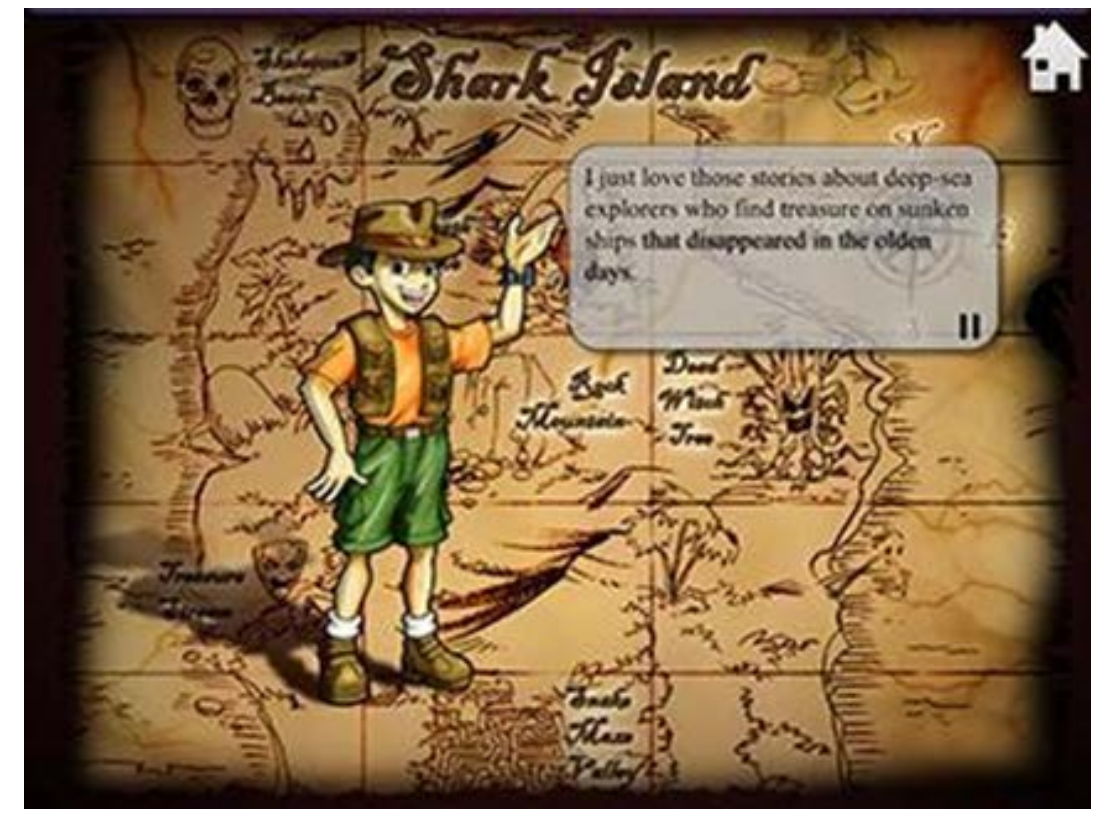

Figura 1 - Tela de apresentação da história pelo protagonista, Kai Fonte: Book app Treasure Kai and the Lost Gold Shark Island

A segunda tela (Fig. 2) mostra o ambiente preferido do personagem, a loja de seus pais, com vários objetos interativos que, ao serem clicados, emitem seu som característico, como uma vitrola que toca música ou um avião que faz barulho de turbina. $O$ texto segue o padrão da caixa de diálogo. 


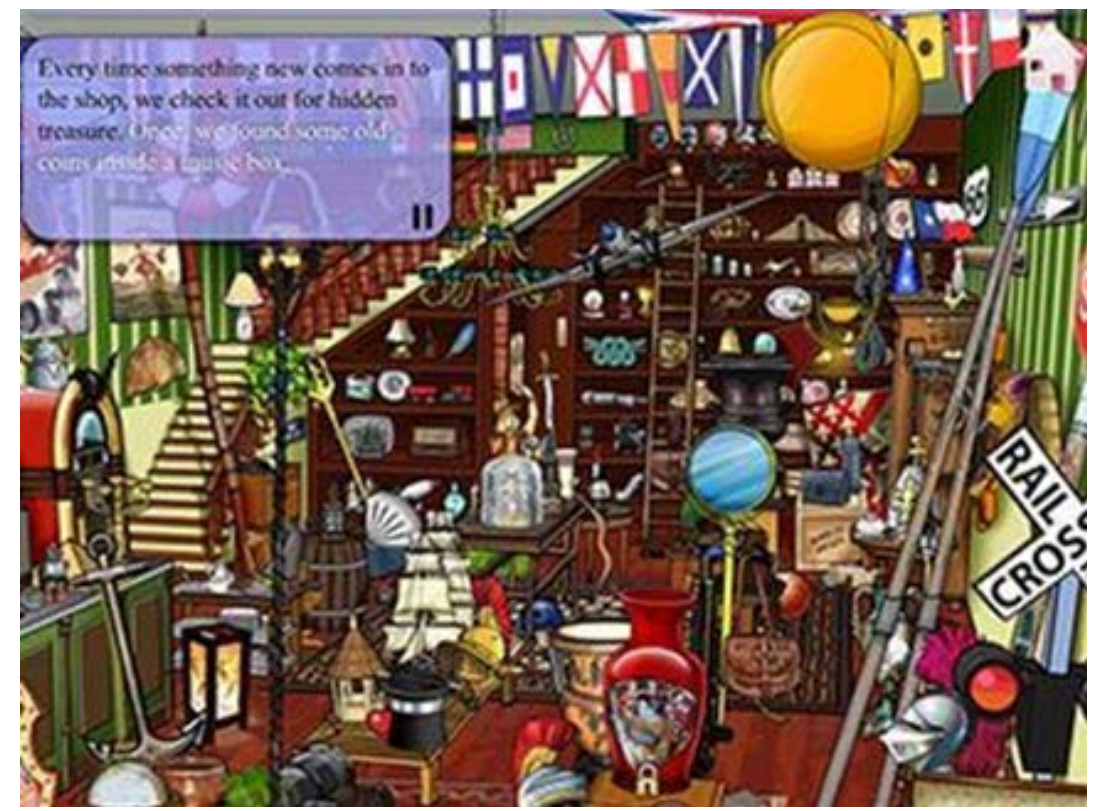

Figura 2 - Ambiente preferido de Kai, a loja de seu pai Fonte: Book app Treasure Kai and the Lost Gold Shark Island

A terceira tela (Fig. 3), além da caixa de texto, mostra as opções de trajetória de leitura a partir de animações nos baús na base da tela. A cada interação os baús são embaralhados para o leitor interagir e optar por um deles.

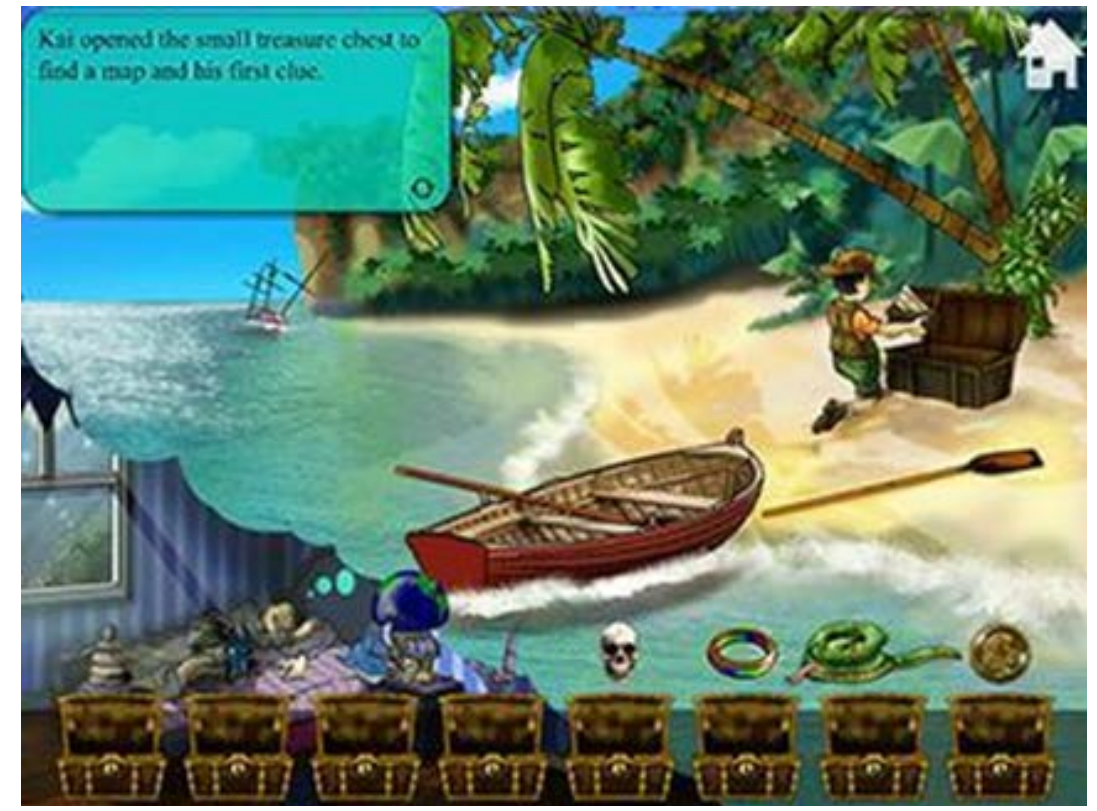

Figura 3 - Opções de trajetórias por meio de interatividade nos baús Fonte: Book app Treasure Kai and the Lost Gold Shark Island

A quarta tela (Fig. 4) mostra o resultado de uma das trajetórias escolhidas, chuva de pedras. Esta tela se diferencia das telas anteriores de narrativa por apresentar um texto instrucional narrado fora da caixa de diálogo. 


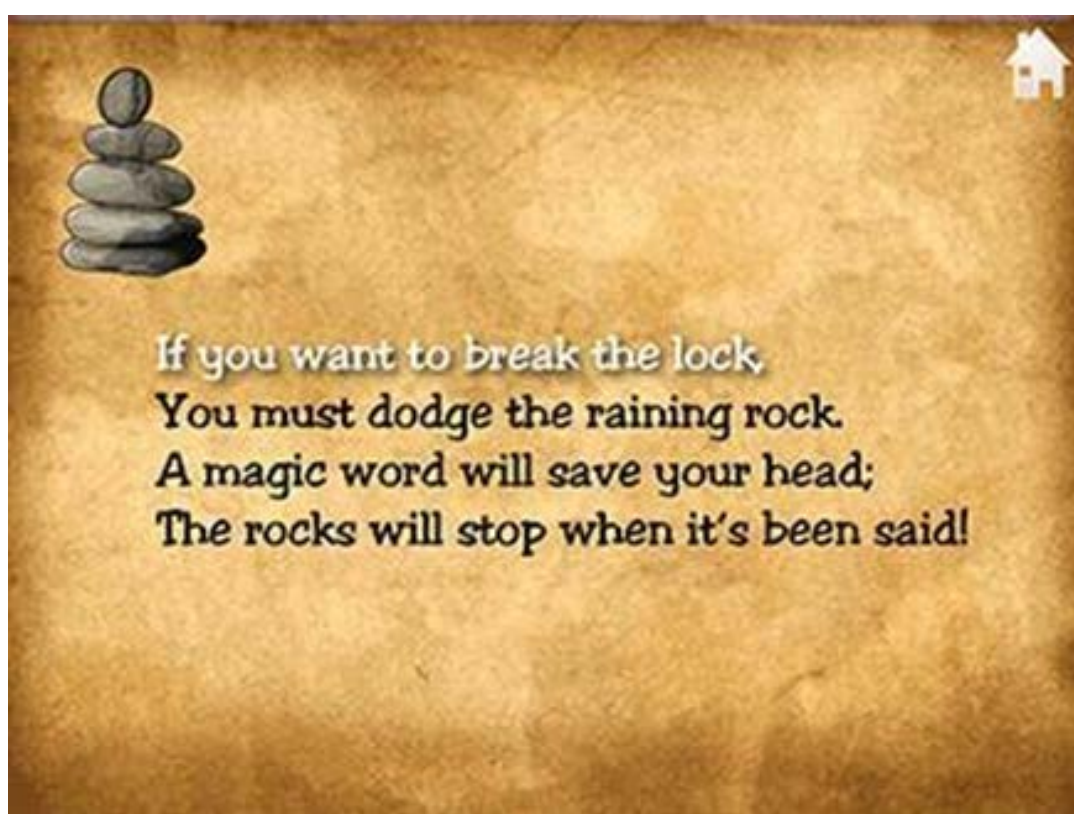

Figura 4 - Tela com um dos resultados escolhidos pelo leitor Fonte: Book app Treasure Kai and the Lost Gold Shark Island

Na sequência é apresentado um quadro que contém os dados da análise das telas anteriormente apresentadas, realizada a partir de sete elementos gráfico-visuais: linha, forma, plano, cor, textura, espaço e volume (dispostos na coluna da esquerda), os quais se cruzam com três grupos de princípios de design: unificação, ênfase e força de percepção (dispostos na primeira linha).

Quadro 1 - Relação dos elementos gráfico-visuais e os princípios de design.

\begin{tabular}{|c|c|c|c|}
\hline & Unificação & Enfase & Força de Percepção \\
\hline linha & $\begin{array}{l}\text { A linha é utilizada em } \\
\text { todas as figuras como } \\
\text { contorno, tornando-as } \\
\text { semelhantes e geran- } \\
\text { do repetição. Além de } \\
\text { delimitar os planos nas } \\
\text { ilustrações e nos obje- } \\
\text { tos interativos. }\end{array}$ & $\begin{array}{l}\text { Em alguns momentos exis- } \\
\text { tem contraste de espessura, } \\
\text { como nos bolsos do colete } \\
\text { e da bermuda do perso- } \\
\text { nagem na Fig. 1. Porém, } \\
\text { nem sempre fica claro seu } \\
\text { critério de variação como, } \\
\text { por exemplo, na Fig. } 2 \text { em } \\
\text { que a âncora localizada no } \\
\text { canto inferior esquerdo da } \\
\text { imagem, mesmo estando } \\
\text { em mesmo plano, possui um } \\
\text { traço com espessura dife- } \\
\text { rente do móvel em que está } \\
\text { apoiada. }\end{array}$ & $\begin{array}{l}\text { A linha utilizada como contorno } \\
\text { das figuras torna explícitos seus } \\
\text { limites e as separa dos demais } \\
\text { elementos. Contudo, em al- } \\
\text { guns casos, a semelhança no } \\
\text { tratamento das linhas dificulta } \\
\text { a diferenciação entre figura e } \\
\text { fundo, como podemos visualizar } \\
\text { na Fig. } 2 \text {. }\end{array}$ \\
\hline
\end{tabular}




\begin{tabular}{|c|c|c|c|}
\hline forma & $\begin{array}{l}\text { Todas as formas utilizadas } \\
\text { nas ilustrações são com- } \\
\text { plexas, com elevado nível } \\
\text { de detalhamento e de } \\
\text { pequena dimensão. As- } \\
\text { sim, em alguns casos fica } \\
\text { difícil apreendê-las indivi- } \\
\text { dualmente. Na Fig. } 2 \text {, por } \\
\text { exemplo, objetos intera- } \\
\text { tivos possuem o mesmo } \\
\text { tratamento que os demais } \\
\text { objetos. Por outro lado, } \\
\text { na Fig. } 3 \text { os baús formam } \\
\text { uma unidade claramente } \\
\text { distinta, devido a simi- } \\
\text { laridade, proximidade, } \\
\text { alinhamento e repetição } \\
\text { de seus elementos, o que } \\
\text { facilita a identificação de } \\
\text { sua qualidade interativa. }\end{array}$ & $\begin{array}{l}\text { Em contraponto às formas } \\
\text { aplicadas às ilustrações, as } \\
\text { caixas de diálogo utilizam } \\
\text { uma figura simples - um } \\
\text { retângulo com os cantos } \\
\text { chanfrados, destacando-se } \\
\text { das demais formas. Na Fig. } \\
2 \text { são utilizadas formas mais } \\
\text { geométricas, em consonân- } \\
\text { cia com o caráter sintético } \\
\text { (não natural) da cidade; ao } \\
\text { contrário das figuras } 1 \text { e } 3 \text { que } \\
\text { utilizam formas mais orgâni- } \\
\text { cas para enfatizar o caráter } \\
\text { natural das paisagens que } \\
\text { representam. }\end{array}$ & $\begin{array}{l}\text { Nas ilustrações é perceptível } \\
\text { a relação entre figura e fun- } \\
\text { do, exceto na Fig. } 3 \text { em que as } \\
\text { formas se misturam devido à } \\
\text { sua semelhança. } \\
\text { O uso de fontes de famílias } \\
\text { e tamanhos diferentes evi- } \\
\text { dencia uma hierarquia da in- } \\
\text { formação, onde os textos de } \\
\text { diálogo, voltados para a in- } \\
\text { teração (Fig. 4), se destacam } \\
\text { dos textos da narrativa (Fig. } 1 \text {, } \\
2 \text { e 3). }\end{array}$ \\
\hline plano & $\begin{array}{l}\text { É possível identificar a } \\
\text { repetição de elementos } \\
\text { dentro do plano, como } \\
\text { o ícone de retorno a tela } \\
\text { inicial localizado no canto } \\
\text { superior esquerdo, e as } \\
\text { caixas de texto sobre as } \\
\text { ilustrações. }\end{array}$ & $\begin{array}{l}\text { Na Fig. } 1 \text { é perceptível um } \\
\text { tratamento diferenciado } \\
\text { das margens do plano, que } \\
\text { representam uma espécie de } \\
\text { moldura que remete a leitu- } \\
\text { ra do mapa do tesouro, em } \\
\text { outro ambiente. }\end{array}$ & $\begin{array}{l}\text { A diferença de dimensão } \\
\text { entre as duas imagens na Fig. } \\
3 \text { torna a ilustração desequi- } \\
\text { librada, observado pelo fato } \\
\text { da imagem de maior dimen- } \\
\text { são se encontrar na parte } \\
\text { superior. }\end{array}$ \\
\hline cor & $\begin{array}{l}\text { Para adaptarem-se ao } \\
\text { cenário, as caixas de texto } \\
\text { mudam de cor, o que } \\
\text { compromete a unidade } \\
\text { visual entre as telas. Já na } \\
\text { tipografia existe um pa- } \\
\text { drão cromático, no qual o } \\
\text { trecho do texto que está } \\
\text { sincronizado com o áudio } \\
\text { muda na cor preta para a } \\
\text { branca, exceto na Fig. } 1, \\
\text { em que sofre o acréscimo } \\
\text { de uma sombra, ao invés } \\
\text { de mudar de cor }\end{array}$ & $\begin{array}{l}\text { O ebook utiliza uma ampla } \\
\text { paleta de cores, quase sempre } \\
\text { divididas em duas escalas bem } \\
\text { definidas: cores frias e cores } \\
\text { quentes. Nas figuras } 1,3 \text { e } 4 \\
\text { fica evidente a predominância } \\
\text { de uma dessas escalas. Ao } \\
\text { contrário do que é utilizado } \\
\text { recorrentemente, na Fig. } 3 \\
\text { o uso de cores brilhantes na } \\
\text { figura com ênfase represen- } \\
\text { tada, neste caso, o sonho do } \\
\text { personagem. }\end{array}$ & $\begin{array}{l}\text { As cores das caixas de texto } \\
\text { possuem contraste com as } \\
\text { ilustrações. Contudo, seu } \\
\text { baixo nível de opacidade } \\
\text { dificulta a legibilidade dos } \\
\text { textos, prejudicando a dis- } \\
\text { tinção entre eles e o fundo } \\
\text { (ilustração), especialmente } \\
\text { nas fontes em branco, mes- } \\
\text { mo que seja possível deslo- } \\
\text { car as caixas de texto sobre } \\
\text { o plano. }\end{array}$ \\
\hline
\end{tabular}




\begin{tabular}{|c|c|c|c|}
\hline textura & $\begin{array}{l}\text { As texturas utilizadas nas } \\
\text { figuras } 1 \text { e } 3 \text { (representan- } \\
\text { do mapas antigos e perga- } \\
\text { minhos) possuem quali- } \\
\text { dades visuais semelhantes } \\
\text { que expressam unidade } \\
\text { entre si e coerência com } \\
\text { o tema da narrativa (busca } \\
\text { ao tesouro). }\end{array}$ & $\begin{array}{l}\text { As texturas foram utili- } \\
\text { zadas com ênfase no vo- } \\
\text { lume e no material por } \\
\text { meio de contrastes tonais } \\
\text { das cores - como a ilus- } \\
\text { tração do espelho (Fig. } 2 \text { ) } \\
\text { e a roupa do personagem } \\
\text { (Fig. 1). }\end{array}$ & $\begin{array}{l}\text { Em algumas telas o equilíbrio } \\
\text { foi comprometido pela va- } \\
\text { riação de estilo de texturas } \\
\text { Como a textura naturalista do } \\
\text { mar em contraponto às tex- } \\
\text { turas expressivas da canoa e } \\
\text { outros elementos (Fig. } 3 \text { ). }\end{array}$ \\
\hline espaço & $\begin{array}{l}\text { A distância entre } \\
\text { essas caixas de texto } \\
\text { e a margem do pla- } \\
\text { no varia a cada tela, } \\
\text { o que compromete } \\
\text { a unidade entre as } \\
\text { telas. }\end{array}$ & $\begin{array}{l}\text { Na Fig. } 2 \text { não existe espaço } \\
\text { de respiro, o que dificulta a } \\
\text { percepção dos elementos e a } \\
\text { trajetória de leitura, já que não } \\
\text { existem pontos de destaque. } \\
\text { Já na Fig. } 4 \text { o espaço de respi- } \\
\text { ro implica em ênfase texto. }\end{array}$ & $\begin{array}{l}\text { Exceto na Fig. } 2 \text {, os espaços } \\
\text { entre as formas estão equi- } \\
\text { librados. Já nas caixas de } \\
\text { textos, suas dimensões fixas } \\
\text { em relação ao texto geram } \\
\text { desequilíbrio (Fig. } 3 \text { ). }\end{array}$ \\
\hline volume & $\begin{array}{l}\text { A representação de } \\
\text { volume se dá pelo trata- } \\
\text { mento de luz e sombra. } \\
\text { Também utiliza a pers- } \\
\text { pectiva, como podemos } \\
\text { identificar nas figuras } 2 \mathrm{e} \\
3 \text {, porém de forma mais } \\
\text { sutil. }\end{array}$ & $\begin{array}{l}\text { A Fig. } 1 \text { se destaca por } \\
\text { aplicar uma sombra pro- } \\
\text { jetada do personagem } \\
\text { sobre o mapa. Já a Fig. } \\
4 \text { não explora o volume, } \\
\text { enfatizando a interação } \\
\text { como objetivo principal. }\end{array}$ & $\begin{array}{l}\text { A representação de vo- } \\
\text { lume aplicada às caixas } \\
\text { de texto, gerada pelo } \\
\text { tratamento de luz e } \\
\text { sombra, é fundamental } \\
\text { para a percepção de sua } \\
\text { posição em primeiro } \\
\text { plano. }\end{array}$ \\
\hline
\end{tabular}

Fonte: Elaborado pelos autores, com base na pesquisa realizada

\section{Discussão dos dados}

A partir desta análise foi possível identificar que a linguagem visual do book app infantil Treasure Kai and the Lost Gold Shark Island foi planejada, em termos de configuração e organização de seus elementos, a partir da aplicação de alguns princípios de design elencados por esta análise. De forma geral, o livro apresenta uma solução gráfica rica na aplicação de recursos visuais e uma boa integração entre estes e os demais recursos (texto, áudio e recursos interativos). Contudo, algumas das soluções aplicadas às telas deste ebook se mostraram mais adequadas do que outras.

Como ponto positivo destaca-se a integração entre texto escrito, áudio e imagem no mesmo plano, sem separação ou omissão, o que torna a interação mais fácil e interessante, sendo uma solução totalmente adequada a uma tela com as dimensões do dispositivo utilizado. Há também a possibilidade de deslocamento da caixa de texto sobre o plano, que explora o recurso de manipulação direta do dispositivo, permitindo que o usuário adapte o layout, de forma interativa, de acordo com sua preferência. $A$ 
utilização do destaque das palavras do texto, sincronizadas com o áudio, favorecem a leitura.

Por outro lado, percebem-se alguns aspectos que comprometeram a qualidade visual do livro como, por exemplo, a falta de consistência entre as telas gerada pela mudança de cor e deslocamento na posição das caixas de texto, bem como pela variação no destaque do texto sincronizado com o áudio (Fig. 2), visível nas telas. Outro ponto comprometedor na qualidade do livro refere-se ao emprego de um número excessivo de formas na mesma imagem (Fig. 3), com o mesmo nível de detalhamento e o mesmo tratamento de sombras e luzes, o que dificulta sobremaneira a percepção individual dos elementos, desvalorizando-os e ocultando suas qualidades interativas. Também foram identificados problemas de legibilidade devido ao baixo nível de opacidade das caixas de texto.

Somando-se a isso, a unificação do estilo gráfico aplicado às ilustrações compromete a ênfase aos objetos interativos na interface visual, o que poderia ter sido explorado por meio de contrastes. Neste caso, o princípio da força de percepção também foi prejudicado, pois em alguns momentos, principalmente na Figura 3, o fluxo de narrativa pode ser interrompido tendo em vista a necessidade de o leitor buscar padrões visuais que possam mostrar os objetos sonoros interativos ou simplesmente mudar a página. O princípio da força da percepção é fundamental para a indicação das áreas interativas.

\section{CONSIDERAÇÕES FINAIS}

Neste estudo foi possivel perceber como a configuração e a organização da linguagem visual, bem como a aplicação de princípios de design, podem influenciar na comunicação da mensagem visual e, por consequência, na interação com o usuário. As soluções aplicadas ao design visual de interface de um ebook interferem na facilidade de leitura, na condução da narrativa e na motivação do usuário. Todos os aspectos da estrutura gráfico-visual atuam de forma integrada. Assim, uma solução equivocada pode comprometer todo o restante.

A análise do book app infantil Treasure Kai and the Lost Gold Shark Island permitiu identificar soluções de organização dos elementos visuais que contribuem para o processo interativo em ambiente digital: o uso de tratamento diferenciado para evidenciar os objetos interativos; as mudanças de plano de fundo para indicar ou enfatizar as alterações de ambiente no fluxo da história; e o uso de contraste (cor, escala ou figura-fundo) para facilitar a percepção dos objetos na interface, indicar hierarquia e ajudar na condução de uma leitura interativa, destacando objetos passíveis de manipulação.

Assim, este estudo mostrou que o modo de enunciação do espaço visual pode contribuir com o processo de leitura, orientando o fluxo narrativo e destacando os recursos de interatividade. Contribui ainda para legibilidade e condução da interação em uma interface visual digital. Isso pode ser alcançado de forma efetiva por meio de parâmetros de utilização dos elementos gráfico-visuais juntamente com os princípios de design. 


\section{REFERÊNCIAS}

BEVILACQUA, Tatiana Silva. 0 conceito de interface no contexto do design. In 3 을 Congresso nacional de design da informação, 2007, Curitiba. Anais...Curitiba: SBDI, 2007.

BIRCHER, K. What makes a good picture book app? The Horn Book Magazine, p.72-78, março/abril, 2012. Disponível na internet por http em: <http://www.hbook. com/2012

/02/using-books/what-makes-a-good-picture-book-app/ >. Acesso em 16 fev. 2014.

COSTELO, Vic et. al. Multimedia Foundations: core concepts for digital design. Waltham, MA - USA: Focal press/Elsevier, 2012.

CULLINAN, Bernice E. et al. Literature and the child. 8. ed. Belmont, USA: Wadsworth Cengage Learning, 2014.

DUARTE, Márcio. Ebook: desvendando os livros feitos de pixels. Brasília: PageLab, 2010. Disponivel na internet por http em: <http://www.slideshare.net/marciom10>. Acesso em 15 março 2014.

GOMES FILHO, João. Gestalt do objeto. São Paulo: Escrituras editora, 2000.

LESSA, Washington Dias. Linguagem visual: algumas considerações. In: LIMA, Guilherme Cunha. Textos selecionados de design. Rio de Janeiro: Ppdesdi Uerj, 2006. Cap. 1. p. 9-23.

LINDEN, Sophie Van der. Para ler o livro ilustrado. São Paulo: Cosac Naify, 2011.

LUPTON, Ellen; PHILLIPS, Jennifer Cole. Novos Fundamentos do Design. São Paulo: Cosac Naify, 2008.

SPALDING, Marcelo. Alice do livro impresso ao e-Book: adaptação de Alice no país das maravilhas de Através do espelho para iPad. Porto Alegre: UFRGS, 2012. 246 p. Tese (doutorado) - Programa de pós-graduação em letras, Faculdade de Letras, Universidade Federal do Rio Grande do Sul, Porto alegre, 2012.

TEIXEIRA, Deglaucy Jorge et. al. Os códigos de linguagem como potencializadores da interação em aplicativos de literatura infantil: uma análise do app cinderella de nosy crow. In: 4o Congresso Internacional CBL do Livro Digital. São Paulo, 2013. Disponivel na internet por http em: <http://www.congressodolivrodigital.com. br/site/ trabalhos-cientificos>. Acesso em 12 fev. 2014. 


\section{Autores}

\section{Deglaucy Jorde Teixeira}

Mestrando pela Instituição: Universidade Federal de Santa Catarina -( UFSC), pós-graduado em Design Gráfico; graduado em Administração de Marketing Florianópolis, Santa Catarina, Brasil email: deglaucyjorgeagmail.com Lattes: http://lattes.cnpq.br/3449963328224045

\section{Juliane Vargas Nunes}

Doutoranda pela Universidade Federal de Santa Catarina (UFSC); mestre em Design e Expressão Gráfica pela Universidade Federal de Santa Catarina (UFSC); bacharela em Design Gráfico pela Universidade Federal de Pelotas (UFPel)

Florianópolis, Santa Catarina, Brasil

julivnagmail.com

Lattes: http://lattes.cnpq.br/6597934311081812

\section{Berenice Santos Gonçalves}

Doutora em Engenharia de Produção pela Universidade Federal de Santa Catarina ( UFSC) em 2004; mestre em Artes Visuais pela Universidade Federal do Rio Grande do Sul (UFRS) em 1997; graduada em Bacharelado e Licenciatura em Artes Visuais pela Universidade Federal de Santa Catarina (UFSC) em 1990

Florianópolis, Santa Catarina, Brasil

berenice@cce.ufsc.br

Lattes: http://lattes.cnpq.br/8382731805850046

\section{Richard Perassi Luiz de Souza}

Doutor em Comunicação e Semiótica pela Universidade Católica de São Paulo (PUC) em 2001; mestre em Educação pela Universidade Federal de Mato Grosso do Sul (UFMS) em 1995; bacharel em Desenho de Propaganda e licenciado em Artes Plásticas pela Universidade Federal de Juiz de Fora (UFJF) em 1986, atualmente professor na Universidade Federal de Santa Catarina (UFSC)

Florianópolis, Santa Catarina, Brasil

richard.perassi@uol.com.br

Lattes: http://lattes.cnpq.br/0396579652444165 este CV: 